Artikel Penelitian

\title{
Analisis Kualitas Air Berdasarkan Parameter Fisika di Wilayah Kota Bengkulu
}

\author{
Fades Br Gultom*, Refpo Rahman, Heriansyah
}

Program Studi D3 Laboratorium Sains, Fakultas Matematika dan IImu Pengetahuan Alam, Universitas Bengkulu, Bengkulu, Indonesia, 38371

INFO ARTIKEL

\section{Sejarah Artikel}

Diterima 9 Februari 2021

Direvisi 2 Juni 2021

Tersedia online 5 Oktober 2021

* Penulis korespondensi: fadesgultom@unib.ac.id

\section{ABSTRAK}

Water is a source of basic human needs. Clean water quality will affect environmental health and all activities in it. This study aimed to measure the quality of the water around beaches, rivers and swamps near settlements in Bengkulu City. The research location consisted of nine points with a radius of 0-2 $\mathrm{km}$ from the beach. Sampling was carried out using the stratified disproportional random sampling method with measured parameters including temperature, total dissolved solids (TDS) and water turbidity. The method used in the data analysis is the STORET scoring system. The samples were tested using TDS and turbidity meter based on the Arduino Uno ATMega 328. Results of temperature measurement showed relatively stable values in the range of $29-30^{\circ} \mathrm{C}$; TDS values were $53-565 \mathrm{mg} / \mathrm{L}$ and water turbidity levels ranged from 90.8 to 1938.1 NTU. Based on the results of the analysis using the STORET scoring system, the water quality status in the study area was included in the medium polluted category (score -15) of 3 test parameters (temperature, TDS and water turbidity).

Keywords: Water quality, physical parameter, STORET method, Bengkulu City

Air merupakan sumber kebutuhan dasar manusia. Kualitas air yang bersih akan mempengaruhi kesehatan lingkungan dan seluruh aktivitas didalamnya. Tujuan penelitian ini adalah untuk mengukur kualitas air yang ada di sekitar pantai, sungai dan rawa dekat pemukiman di Kota Bengkulu. Lokasi penelitian terdiri dari 9 titik dengan radius $0-2 \mathrm{~km}$ dari pinggir pantai. Pengambilan sampel dilakukan dengan menggunakan metode stratified disproportional random sampling dengan parameter yang diukur diantaranya suhu, total dissolved solids (TDS) dan kekeruhan air. Metode yang digunakan dalam analisis data yaitu sistem penilaian STORET. Pengujian sampel dilakukan dengan TDS meter dan turbidity meter berbasis Arduino Uno ATMega 328. Hasil pengukuran suhu menunjukkan nilai yang relatif stabil dengan kisaran $29-30^{\circ} \mathrm{C}$; nilai TDS antara 53-565 mg/L dan tingkat kekeruhan air pada rentang 90,8-1938,1 NTU. Berdasarkan hasil analisis menggunakan sistem penilaian STORET, status mutu air di wilayah penelitian termasuk pada kategori cemar sedang (skor -15) berdasarkan 3 parameter uji (suhu, TDS dan kekeruhan air).

Kata kunci: Kualitas air, parameter fisika, metode STORET, Kota Bengkulu

\section{Pendahuluan}

Air merupakan sumber daya alam terbatas yang keberadaannya sangat dibutuhkan untuk keberlangsungan hidup seluruh mahluk hidup [1]. Meskipun terbatas, namun sumber air ini dapat diperbaharui dengan siklus hidrologi [2]. Beberapa indikator yang mencirikan air yang baik dan layak konsumsi diantaranya tidak ada rasa, bau, warna dan terhindar dari senyawa kimia berbahaya [3, 4]. 
Air yang berkualitas akan memberikan efek kenyamanan dan kesehatan dalam lingkungan. Penentu kualitas air dilihat dari kondisi geologis, terhindar dari pencemaran limbah, dan pola aktivitas yang baik dari manusia dalam menjaga lingkungan. Menurunnya kualitas air dapat mempengaruhi keselamatan hidup manusia, hewan maupun tumbuhan [5]. Oleh karena itu, perlu adanya pemantauan kualitas air disekitar lingkungan tempat tinggal maupun akses lokasi umum guna melihat dampak yang akan terjadi dalam jangka waktu tertentu. Apabila terjadi penurunan kualitas air, segera dilakukan pencegahan dan penanggulangan agar tidak menimbulkan pencemaran lebih lanjut [1, 3].

Penentuan kualitas air pada penelitian ini didasarkan pada analisis parameter fisika seperti banyaknya partikel terlarut dalam air atau total dissolved solids (TDS), kekeruhan air dan suhu. Parameter baku mutu kualitas air bersih untuk hygiene sanitasi juga diatur oleh Permenkes RI No 32 Tahun 2017 bahwa tingkat kekeruhan air maksimal sebesar 25 NTU dan nilai TDS maksimal sebesar $1000 \mathrm{mg} / \mathrm{L}$ [4]. Parameter tersebut dipilih berdasarkan faktor penyebab penurunan kualitas air. Pada penelitian ini, pengambilan contoh air dilakukan di tiga lokasi berbeda yaitu sekitar pantai, sekitar sungai dan sekitar air rawa dekat perumahan. Pengambilan sampel dilakukan dengan menggunakan metode stratified disproportional random sampling. Metode stratified disproportional random sampling merupakan teknik pengambilan sampel acak dari tiap kelompok dengan karakteristik populasi yang bervariasi [6]. Pengambilan sampel secara acak dimaksudkan agar setiap lokasi terwakili oleh beberapa sampel sehingga keseluruhan sampel untuk penentuan kualitas air di Wilayah Kota Bengkulu dapat diketahui.

\section{Bahan dan Metode}

\subsection{Bahan}

Bahan yang digunakan dalam pengujian adalah sampel air yang diambil dari 9 titik lokasi penelitian di wilayah Kota Bengkulu (Gambar 1).

\subsection{Pengambilan Sampel}

Penelitian dilakukan dengan metode deskriptif kuantitatif yaitu melakukan pengukuran terhadap parameter kualitas air dengan mengambil secara acak sampel air pada 9 titik lokasi di sekitar pantai, sekitar sungai dan sekitaran rawa dekat pemukiman warga. Lokasi sampel satu (S1), dua (S2) dan tiga (S3) terletak disekitar pantai dengan radius dari tepi pantai berkisar 100-1000 m. Lokasi sampel empat (S4), lima (S5) dan enam (S6) terletak di sekitar rawa dekat pemukiman padat penduduk, dengan radius dari tepi pantai berkisar 700-2000 m. Lokasi sampel tujuh (S7), delapan (S8) dan sembilan (S9) terletak di sekitar sungai dengan radius dari tepi pantai berkisar 200-4000 m. Peta lokasi pengambilan sampel dapat dilihat pada Gambar 1.

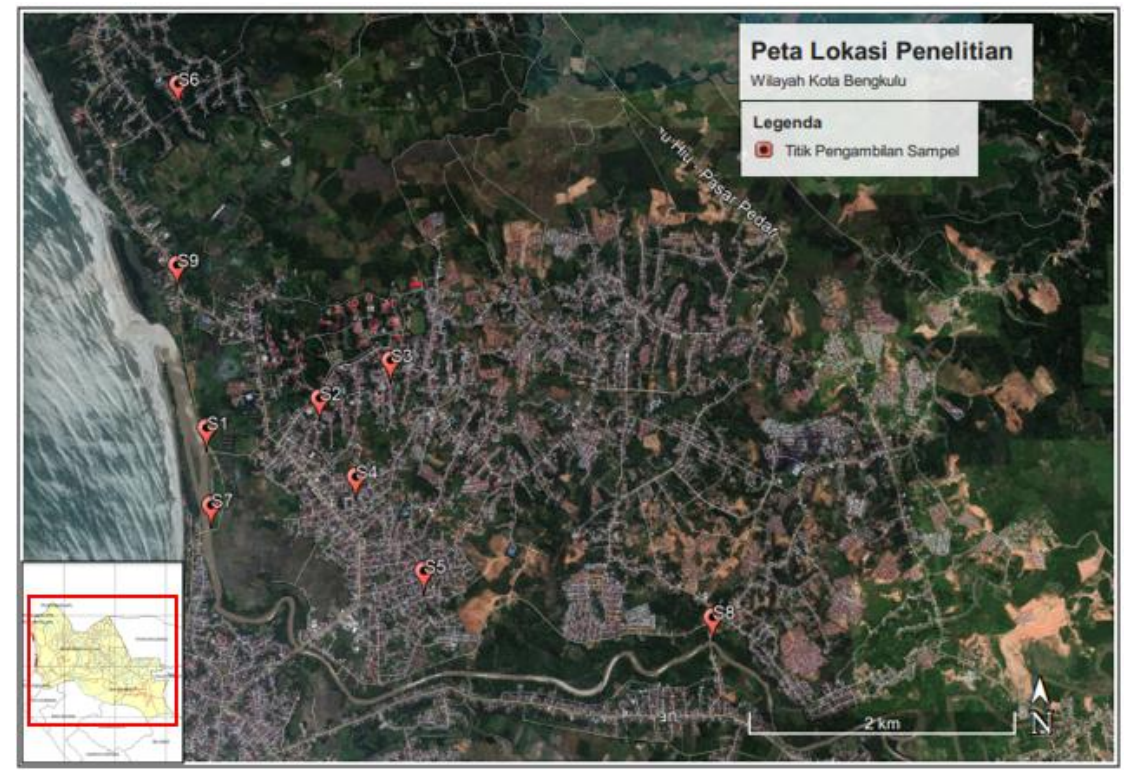

Gambar 1. Peta lokasi pengambilan sampel (sumber: modifikasi dari google earth dan arcgis)

\subsection{Prosedur Penelitian}

Penelitian dimulai dengan pengambilan sampel sesuai dengan lokasi yang telah ditetapkan. Tiga parameter yang meliputi total dissolved solids (TDS), suhu, dan kekeruhan air diukur secara langsung di lokasi pengambilan sampel. 
Adapun alat yang digunakan dalam pengujian sampel adalah turbidity meter berbasis Arduino Uno ATMega 328 sebagai alat untuk mengukur kekeruhan dan TDS meter Tipe Hanna HI98301 sebagai alat untuk mengukur TDS.

\subsection{Analisis Data}

Analisis data statistik deskriptif digunakan untuk menganalisis rata-rata, nilai tengah, standar deviasi dan frekuensi dari masing-masing parameter. Evaluasi kualitas air dilakukan dengan membandingkan hasil analisis dengan baku mutu yang ditetapkan pemerintah RI melalui Permenkes Nomor 32 tahun 2017 tentang standar baku mutu kesehatan lingkungan dan persyaratan kesehatan air untuk keperluan hygiene sanitasi, kolam renang, solus per aqua, dan pemandian umum [7].

Metode yang digunakan untuk penentuan status mutu air adalah metode STORET (Storage and Retrieved Quality Data System) [8]. Metode ini digunakan untuk mengetahui parameter yang memenuhi atau melampaui batas status baku mutu air. Penentuan status baku mutu air ini berdasarkan analisis parameter fisika yang kemudian hasil pengukuran tersebut akan dibandingkan dengan nilai baku mutu dari Permenkes No 32 tahun 2017. Hasil pengukuran yang memenuhi nilai baku mutu (hasil pengukuran < nilai baku mutu) diberi skor 0 , sedangkan hasil pengukuran yang tidak memenuhi nilai baku mutu (hasil pengukuran > nilai baku mutu) maka diberi skor (Tabel 1).

Tabel 1. Penentuan Sistem Nilai Status Mutu Air

\begin{tabular}{ccccc}
\hline \multirow{2}{*}{ Jumlah Contoh*) } & Nilai & \multicolumn{3}{c}{ Parameter } \\
\cline { 3 - 5 } & Maksimum & Fisika & Kimia & Biologi \\
\hline \multirow{3}{*}{$<10$} & Minimum & -1 & -2 & -3 \\
& Rata-Rata & -3 & -2 & -3 \\
\multirow{3}{*}{$\geq 10$} & Maksimum & -2 & -6 & -9 \\
& Minimum & -2 & -4 & -6 \\
& Rata-Rata & -6 & -12 & -6 \\
\hline
\end{tabular}

Sumber : Keputusan Menteri Lingkungan Hidup Nomor 115 Tahun 2003 [8]

*) Jumlah parameter yang digunakan untuk penentuan status mutu air

Kualitas air dinilai berdasarkan ketentuan sistem STORET yang dikeluarkan oleh EPA (Enviromental Protenction Agency) dengan mengklasifikasikan mutu air menjadi empat kelas, yaitu:

(1) Kelas A : Baik sekali, skor 0, memenuhi baku mutu

(2) Kelas B : Baik, skor -1 sampai dengan -10, cemar ringan

(3) Kelas C : Sedang, skor -11 sampai dengan -30, cemar sedang

(4) Kelas D : Buruk, skor $\geq 31$, cemar berat

\section{Hasil dan Pembahasan}

Penentuan kualitas air di wilayah kota Bengkulu meliputi Kecamatan Muara Bangkahulu dan Kecamatan Sungai Serut. Pengambilan 9 sampel air dilakukan di sekitar pantai, perumahan di sekitar rawa dan air sungai yang sering digunakan masyarakat dalam pemenuhan kebutuhan hygiene sanitasi. Hasil pengukuran suhu memperlihatkan variasi data yang relatif stabil pada rentang $29,8-30,1^{\circ} \mathrm{C}$ (Gambar 2). Nilai ini menunjukkan bahwa suhu masih berada pada rentang suhu normal perairan tropis, yang berkisar antara $23-32^{\circ} \mathrm{C}$ [9]. Suhu memiliki peran dalam proses metabolisme air, kenaikan suhu pada suatu perairan dapat menyebabkan peningkatan konsumsi oksigen biota air [1]. Selain itu, tinggi rendahnya suhu juga berpengaruh terhadap laju reaksi kimia serta daya larut oksigen dalam air [9]. Semakin tinggi suhu suatu perairan maka laju reaksi kimia dan daya larut oksigen akan semakin cepat.

Pada hasil pengukuran TDS atau jumlah zat terlarut dalam air menunjukkan data yang cukup bervariasi di rentang 53 - $565 \mathrm{mg} / \mathrm{L}$ (Gambar 3). Nilai TDS yang paling tinggi ditemukan pada lokasi sampling ke 3 sebesar $565 \mathrm{mg} / \mathrm{L}$. Lokasi ini berada dekat dengan kampus, perumahan dan area kos-kosan mahasiswa. Sumber tercemarnya area ini banyak disebabkan oleh buangan limbah rumah tangga dan kos-kosan, yang mengakibatkan bau dan rasa air yang tidak enak serta mengurangi tingkat kadar oksigen terlarut dalam air [2]. TDS yang tinggi juga akan mengurangi tingkat kejernihan air. Hal ini tentu akan menghambat sinar matahari masuk sehingga memperlambat proses fotosintesis [3]. Namun berdasarkan permenkes RI No 32 Tahun 2017 bahwa hasil pengukuran TDS ini masih dibawah batas maksimal yaitu $1000 \mathrm{mg} / \mathrm{L}$.

Sifat optik air dapat tergambarkan melalui tingkat kekeruhan air. Hal ini ditentukan berdasarkan banyaknya cahaya yang diserap dan dipancarkan oleh bahan-bahan yang terdapat di dalam air [10]. Kekeruhan erat hubungannya dengan padatan yang tersuspensi. Semakin tinggi tingkat kekeruhan air, semakin banyak padatan yang tersuspensi. Output yang dihasilkan dari alat uji ini berupa nilai kekeruhan air (NTU). Pada pengukuran tingkat kekeruhan air diperoleh nilai pada 
rentang 90,8-1938,1 NTU. Nilai yang paling tinggi ditemukan pada lokasi sampling 7 dan 8 dengan nilai berturut-turut yaitu 1938,1 NTU dan 1090,5 NTU.

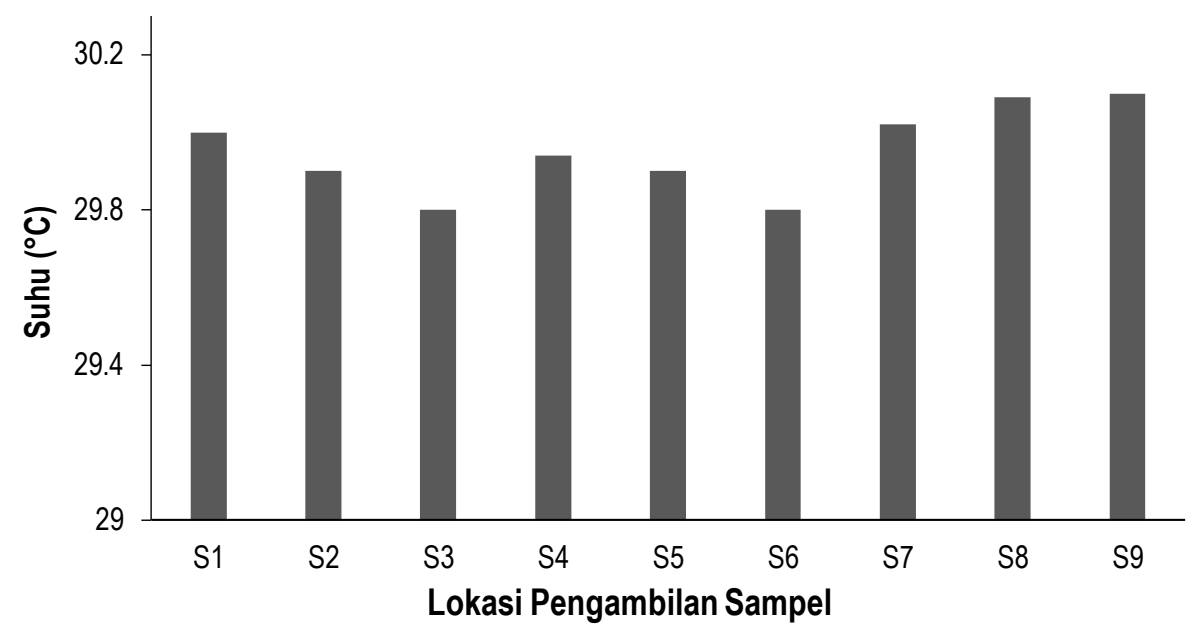

Gambar 2. Suhu pada lokasi pengambilan sampel.

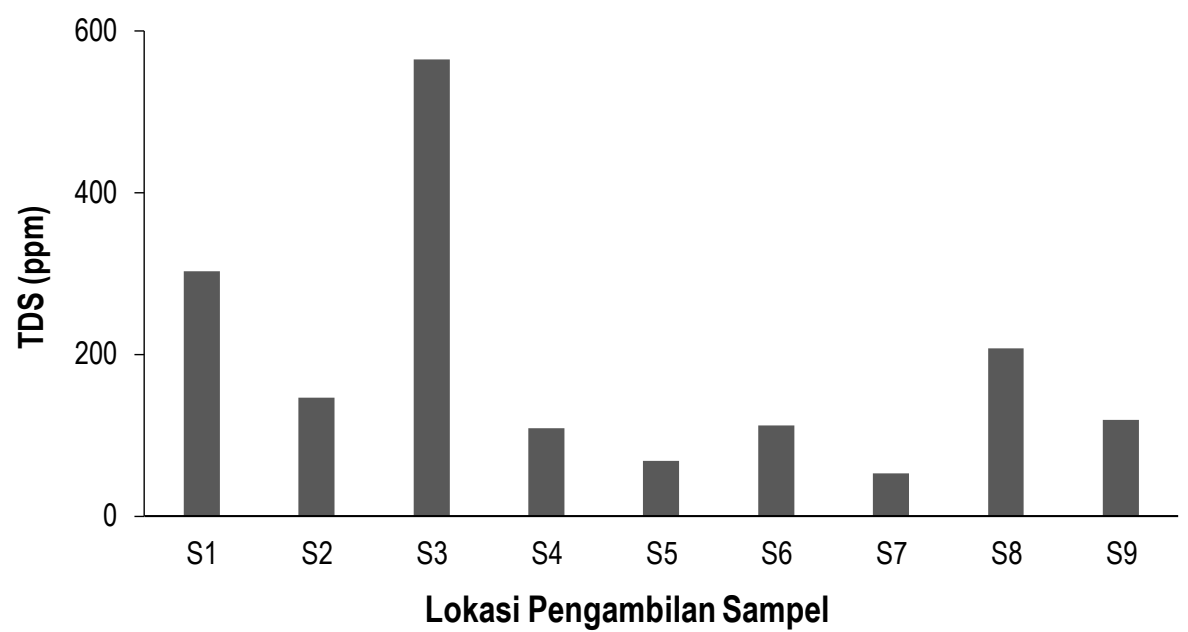

Gambar 3. Total dissolved solids (TDS) pada lokasi pengambilan sampel.

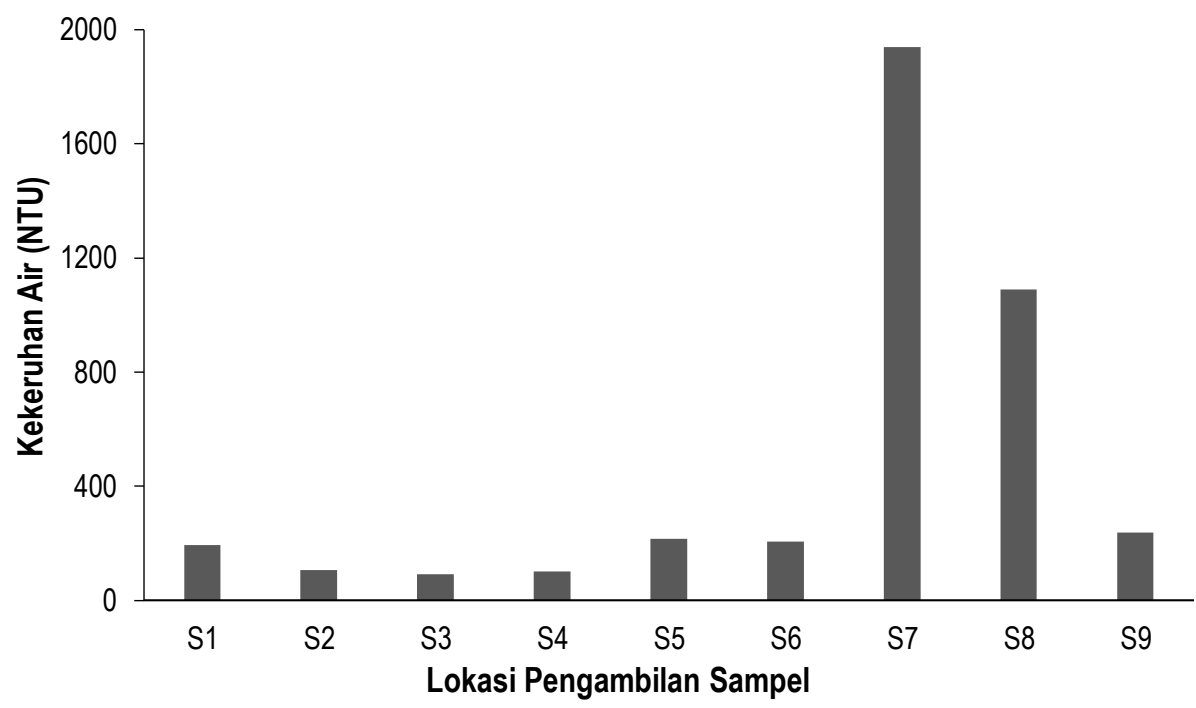

Gambar 4. Kekeruhan air pada lokasi pengambilan sampel. 
Berdasarkan hasil pengukuran tingkat kekeruhan air, keseluruhan nilai yang diperoleh telah melampaui batas maksimum baku mutu air yang ditetapkan pemerintah yaitu 25 NTU. Salah satu faktor yang mempengaruhi tingginya tingkat kekeruhan air dilokasi tersebut sebagian besar diakibatkan oleh organic pollutant dari limbah pabrik Hulu DAS Bengkulu [11]. Limbah cair pabrik karet dan penambangan batu bara menjadi efek buangan yang sangat membahayakan sungai $[11,12]$. Aktifitas penambangan batu bara seperti proses pemisahan batu bara dengan sulfur, proses pembakaran batu bara yang tidak sempurna akan menyebabkan munculnya polycyclic aromatic hydrocarbons (PAHs) [11, 13]. Zat kimia berbahaya dari limbah pabrik yang mencemari sungai tentu dapat menyebabkan kekeruhan air dan ketergangguan ekosistem didalamnya.

Berdasarkan penilaian dengan sistem STORET, status mutu air di wilayah penelitian tergolong cemar sedang (skor = -15) berdasarkan 3 parameter fisik (suhu, TDS, dan kekeruhan air) (Tabel 2). Parameter yang mempengaruhi kondisi penurunan kualitas air tejadi pada tingkat kekeruhan air yang melampaui batas maksimum baku mutu yang ditetapkan pemerintah RI no 32 tahun 2017 yaitu sebesar 25 NTU. Seluruh nilai pada 9 lokasi pengambilan sampel menunjukkan hasil yang jauh melebihi batas maksimum baku mutu kekeruhan air. Parameter lain seperti TDS juga tergolong tinggi (mencapai $565 \mathrm{mg} / \mathrm{L}$ ) namun masih dibawah baku mutu yang ditetapkan pemerintah yaitu sebesar $1000 \mathrm{mg} / \mathrm{L}$.

Tabel 2. Pengukuran Kualitas Air di Wilayah Kota Bengkulu

\begin{tabular}{|c|c|c|c|c|c|c|}
\hline \multirow{2}{*}{ Parameter Fisika } & \multirow{2}{*}{ Baku mutu } & \multirow{2}{*}{ Satuan } & \multicolumn{3}{|c|}{ Hasil Pengukuran } & \multirow{2}{*}{ Skor } \\
\hline & & & Maximum & Minimum & Rata-rata & \\
\hline Suhu & \pm 3 & ${ }^{\circ} \mathrm{C}$ & 30,1 & 29,8 & 29,95 & -3 \\
\hline TDS (Zat Padat Terlarut) & 1000 & $\mathrm{mg} / \mathrm{L}$ & 565 & 53,02 & 309,1 & 0 \\
\hline Tegangan & - & Volt & 4,018 & 3,04 & 3,53 & - \\
\hline Kekeruhan Air & 25 & NTU & 1938,1 & 90,8 & 1014,45 & -12 \\
\hline \multicolumn{6}{|c|}{ Jumlah Skor } & -15 \\
\hline
\end{tabular}

Faktor penyebab adanya penurunan kualitas air di wilayah studi dapat disebabkan oleh beberapa faktor seperti kondisi geologis batuan, struktur tanah dan tingkat ketercemaran area tersebut. Tingkat ketercemaran di area sungai dan pantai juga disebabkan oleh merine debris (sampah laut). Sampah laut organik dan anorganik banyak berasal dari muara sungai dan aktifitas warga di hulu sungai, yang kemudian terbawa hingga ke hilir sungai [14]. Sampah yang berserakan juga terdapat di hampir sepanjang pantai zakat kota Bengkulu. Pola kebiasaan masyarakat membuang sampah sembarangan mengakibatkan sampah menumpuk dilaut dan terdeposit ke wilayah pesisir (Gambar 5 (a)). Kondisi air di tepi pantai yang berbusa dan kotor memperlihatkan kondisi ketercemaran air laut akibat sampah tersebut (Gambar $\mathbf{5}$ (b)). Selain itu, aktivitas penambangan batu bara, pengerukan pasir dan industri karet di Sub DAS Hilir Sungai Bengkulu juga menjadi salah satu penyebab pencemaran air di wilayah studi $[11,15]$. Limbah cair dari industri karet yang dibuang di hulu DAS Bengkulu juga berpengaruh di bagian hilir sungai [12]. Ketercemaran air sungai ini bukan hanya merusak ekosistem sungai tetapi juga mendorong timbulnya penyakit bagi warga sekitar daerah aliran sungai. Namun, diperlukan pemantauan berkala dan penelitian lanjutan dengan menambah parameter kimia dan biologi untuk memperkuat hasil analisis data pada penelitian ini.
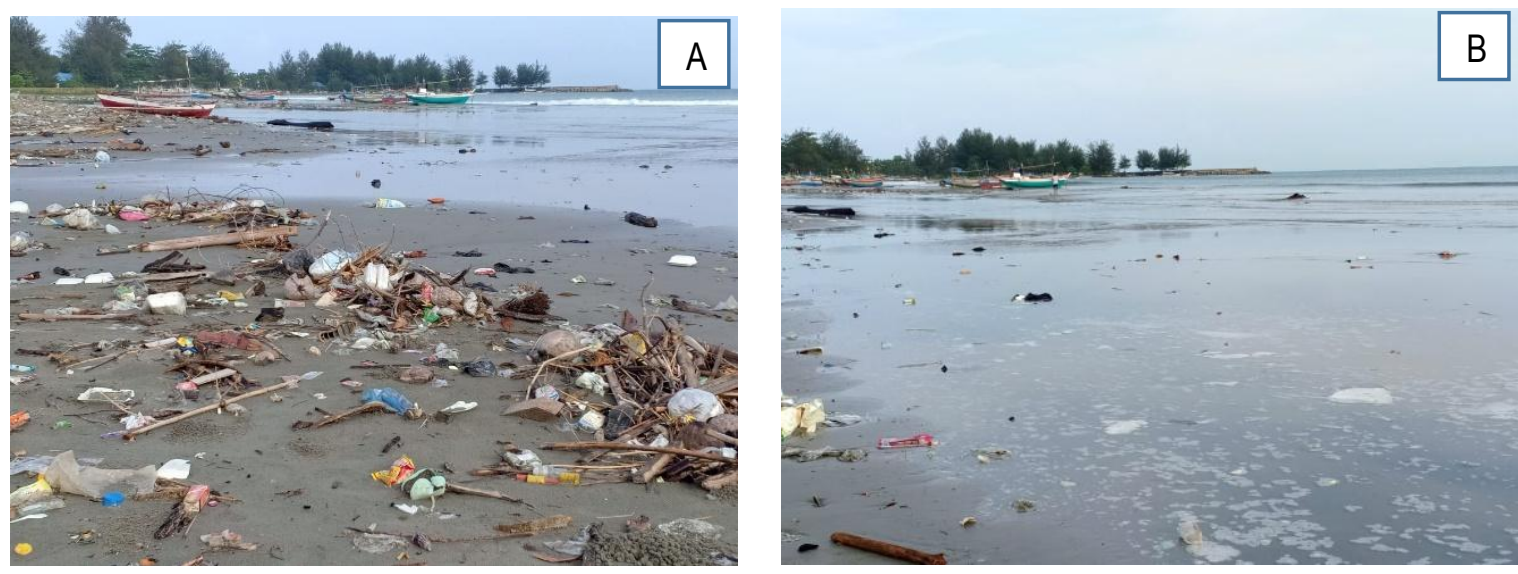

Gambar 5. (A) Kondisi pantai zakat kota Bengkulu yang penuh dengan sampah, dan (B) Kondisi air laut ditepi pantai zakat Kota Bengkulu. 


\section{Kesimp ulan}

Hasil pengukuran pada 9 titik pengambilan sampel, data suhu menunjukkan nilai yang relatif stabil dengan kisaran 29-30 ${ }^{\circ} \mathrm{C}$; nilai TDS antara 53-565 mg/L dan tingkat kekeruhan air pada rentang 90,8-1938,1 NTU. Berdasarkan hasil analisis menggunakan sistem penilaian STORET, status mutu air di wilayah penelitian termasuk pada kategori cemar sedang (skor -15) dari 3 parameter uji yaitu suhu, TDS dan kekeruhan air.

\section{Ucapan Terima Kasih}

Penulis mengucapkan terima kasih kepada Universitas Bengkulu yang telah mendanai penelitian ini melalui dana RBA FMIPA dengan nomor kontrak penelitian: 2048/UN30.12/HK/2020.

\section{Daftar Pustaka}

[1] D. A. Triawan, D. Notriawan, \& G. Ernis, "Penentuan Status Mutu Air Tanah Dangkal di Sekitar Tempat Pembuangan Akhir Sampah (TPA) Air Sebakul Kota Bengkulu Menggunakan Metode Storet: A Cross-Sectional Study", Jurnal Kimia Riset, vol. 5. No. 1, pp. 22-28, 2020.

[2] S. Packialakshmi, M. Deb, \& H. Chakraborty, "Assessment of Groundwater Quality Index in and around Sholinganallur Area, Tamil Nadu", Indian Journal of Science and Technology, vol. 8, no, 36, pp. 1-7, 2015.

[3] T. Akter, F. T. Jhohura, F. Akter, T. R. Chowdhury, S. K. Mistry, D. Dey, M. K. Barua, M. A. Islam, \& M. Rahman, "Water Quality Index for Measuring Drinking Water Quality in Rural Bangladesh: a Cross- Sectional Study", Journal of Health, Population and Nutrition, vol. 35, no. 4, pp. 1-12. 2016.

[4] R. P. Wirman, I. Wardhana, \& V. A. Isnaini, "Kajian Tingkat Akurasi Sensor pada Rancang Bangun Alat Ukur Total Dissolved Solids (TDS) dan Tingkat Kekeruhan Air", Jurnal Fisika, vol. 9, no. 1, pp. 37-46, 2019.

[5] Kahirun, L. O. Siwi, R. A. Surya, L. O. M Erif, A. Yasin \& Ifrianty, "Indikator Kualitas Air Sungai dengan Menggunakan Makroinvertebrata di Sungai Wanggu," Ecogreen, vol. 5, no. 1, pp. 63-67, 2019.

[6] S. F. Ulya, Y. L. Sukestiyarno, \& P. Hendikawati, "Analisis Prediksi Quick Count dengan Metode Stratified Random Sampling dan Estimasi Confidence Interval Menggunakan Metode Maksimum Likelihood," Unnes Journal of Mathematics, vol. 7, no. 1, pp. 108-119, 2018.

[7] Peraturan Pemerintah Republik Indonesia Nomor 82 Tahun 2001 Tentang Pengelolaan Kualitas Air dan Pengendalian Air, Tambahan Lembaran Negara Republik Indonesia Nomor 4161, 2001.

[8] Menteri Negara Lingkungan Hidup, Keputusan Menteri Negara Lingkungan Hidup Nomor 115 Tahun 2003 Tentang Pedoman Penentuan Status Mutu Air, 2003.

[9] R. Siburian, L. Simatupang, \& M. Bukit, "Analisis Kualitas Perairan Laut Terhadap Aktivitas di Lingkungan Pelabuhan Waingapu-Alor Sumba Timur," Jurnal Pengabdian Kepada Masyarakat, vol. 23, no. 1, pp. 225-232, 2017.

[10] N. E. Nuzula \& Endarko, "Rancang Bangun Alat Ukur Kekeruhan Air Berbasis Mikrokontroler", Berkala Fisika, vol.16, no. 4, pp. 111-118, 2013.

[11] J. T. Pareke \& D. A. Putra, "Model Penyelesaian Konflik Kewenangan dalam Hal Timbulnya Dampak Dumping Limbah Batu Bara: Studi Kasus pada Pemerintah Kota Bengkulu dengan Pemerintah Kabupaten Bengkulu Tengah," Padjadjaran Jurnal IImu Hukum, vol. 1, no. 2, pp. 301-312, 2014.

[12] M. Belladona, "Analisis Tingkat Pencemaran Sungai Akibat Limbah Industri Karet di Kabupaten Bengkulu Tengah", dalam Seminar Nasional Sains dan Teknologi Fakultas Teknik Universitas Muhammadiyah Jakarta, 2017, pp. 1-7.

[13] P. C. Bhomick, A. Supong, \& D. Sinha, "Organic Pollutants in Water and Its Remediation Using Biowaste Activated Carbon as Greener Adsorbent," International Journal of Hydrology, vol.1, no. 3, pp. 91-92, 2017.

[14] Y. Johan, P. P. Renta, A. Muqsit, D. Purnama, L. Maryani, P. Hiriman, F. Rizky, A. F. Astuti, \& T. Yunisti, "Analisis Sampah Laut (Marine Debris) di Pantai Kualo Kota Bengkulu", Jurnal Enggano, vol. 5, no. 2, pp. 273-289, 2020.

[15] Supriyono, P. Iskarni, \& E. Barlian, "Kajian Dampak Penambangan Batubara Terhadap Kualitas Air dan Arahan Kebijakan Mitigasi Sungai di Sub Das Hilir Sungai Bengkulu”, Jurnal Geografi, vol. 4, no. 2, pp. 185-192, 2015. 